\title{
Kategorisasi Berita Menggunakan Metode Pembobotan TF.ABS dan TF.CHI
}

\author{
Muhammad Arif Kurniawan ${ }^{\# 1}$, Yuliant Sibaroni ${ }^{\# 2}$, Kemas Muslim Lhaksmana ${ }^{\# 3}$ \\ \# Fakultas Informatika, Universitas Telkom, Bandung \\ ${ }^{1}$ marifk@students.telkomuniversity.ac.id \\ 2 yuliant@telkomuniversity.ac.id \\ ${ }^{3}$ kemasmuslim@telkomuniversity.ac.id
}

\begin{abstract}
With the current technological advances, news can be found easily and totaling very much in digital form causing the need for a technique to categorize the news into specific topics to make it easier for readers to find the news according to the desired topic. Text categorization is a technique that can categorize news into predefined topics automatically. One important process in categorization is feature extraction where unigram binary is one of the basic feature extraction compared to term weighting which in this study will use the weighting method TF.ABS and TF.CHI to obtain optimal news categorization results. Based on the test results, the average accuracy obtained from three data sources on unigram binary feature extraction of $90.44 \%$. While on the weighting method TF.ABS of $95.74 \%$ and TF.CHI of $95.87 \%$. Based on the results of the accuracy, it can be concluded that the term weighting is better than the unigram binary. The weighting methods of TF.ABS and TF.CHI are both good in categorization because they do not differ significantly in performance. Other test results show that the stemming process does not have much effect on the accuracy of news categorization, but this process can make up to $45 \%$ time efficiency.
\end{abstract}

Keywords: Feature extraction, term weighting, text categorization, TF.ABS, TF.CHI, unigram binary.

\begin{abstract}
Abstrak
Dengan kemajuan teknologi saat ini, berita dapat ditemukan dengan mudah dan berjumlah sangat banyak dalam bentuk digital yang menyebabkan diperlukannya suatu teknik untuk mengkategorikan berita-berita tersebut ke dalam topik tertentu agar mempermudah pembaca menemukan berita sesuai dengan topik yang diinginkan. Kategorisasi teks merupakan suatu teknik yang dapat mengkategorikan berita ke dalam topik yang telah ditentukan secara otomatis. Salah satu proses yang penting dalam kategorisasi adalah ekstraksi fitur yang mana unigram binary merupakan salah satu ekstraksi fitur yang dasar dibandingkan dengan term weighting yang dalam penelitian ini akan menggunakan metode pembobotan TF.ABS dan TF.CHI untuk memperoleh hasil kategorisasi berita yang optimal. Berdasarkan hasil pengujian, rata-rata akurasi yang didapatkan dari tiga sumber data pada ekstraksi fitur unigram binary sebesar $90.44 \%$. Sedangkan pada metode pembobotan TF.ABS sebesar $95.74 \%$ dan TF.CHI sebesar $95.87 \%$. Berdasarkan hasil akurasi tersebut, dapat disimpulkan bahwa term weighting lebih baik dibandingkan dengan unigram binary. Metode pembobotan TF.ABS dan TF.CHI sama-sama baik dalam kategorisasi karena tidak berbeda secara signifikan dalam performansinya. Pada hasil pengujian lainnya menunjukkan bahwa proses stemming tidak memberikan banyak pengaruh terhadap akurasi kategorisasi berita, namun proses ini dapat mengefisiensikan waktu hingga $45 \%$.
\end{abstract}

Kata Kunci: Ekstraksi fitur, kategorisasi teks, term weighting, TF.ABS, TF.CHI, unigram binary. 
M.Arif KurniaWAn et.al.

\section{Pendahuluan}

Dengan perkembangan teknologi informasi dan komunikasi saat ini, berita dapat ditemukan dengan mudah dan berjumlah sangat banyak dalam bentuk digital yang berasal dari berbagai sumber. Banyaknya jumlah berita ini menyebabkan diperlukannya suatu teknik pengolahan berita-berita tersebut ke dalam satu atau lebih topik yang telah didefinisikan sebelumnya agar dapat mempermudah pembaca memilih berita sesuai seperti topik yang diinginkan. Berdasarkan permasalahan tersebut, upaya yang dapat dilakukan adalah menerapkan kategorisasi teks untuk mengelompokkan berita berdasarkan topiknya [1].

Kategorisasi pada berita diperlukan suatu data yang terstruktur, namun data yang didapatkan adalah data yang tidak terstruktur atau data yang masih mentah. Permasalahan ini sering dijumpai karena berita yang didapatkan dengan mudah ini berasal dari internet (digital) [2]. Oleh sebab itu, pada kategorisasi teks terdapat suatu proses yang merubah data tersebut menjadi data yang terstruktur yaitu proses text preprocessing yang terdiri dari word tokenization, case folding, stopwords removing, dan word stemming [3]. Selain itu, feature extraction merupakan salah satu proses yang penting dalam kategorisasi yang mana kita dapat menggunakan model unigram binary sebagai teknik dasarnya. Model tersebut memberikan nilai feature dengan nilai binary (Nilai 0 untuk feature yang tidak ada dalam dokumen dan nilai 1 untuk feature yang terdapat dalam dokumen) [4]. Nilai binary ini kurang detail untuk menunjukkan ukuran tingkat kontribusi feature terhadap penentuan kategori karena tidak mempertimbangkan frekuensi kemunculan feature tersebut pada suatu dokumen, untuk menanggulanginya maka adanya suatu proses yang memberikan bobot pada masing-masing feature yang dikenal dengan istilah term weighting. Term weighting memiliki banyak metode yang dapat digunakan, seperti TF.IDF, TF.RF, TF.IG, TF.OR, TF.CHI, TF.ABS, dan sebagainya. Metode pembobotan yang digunakan akan memberikan pengaruh terhadap performansi kategorisasi suatu dokumen [5].

Penelitian ini menggunakan metode pembobotan TF.ABS dan TF.CHI yang memperhitungkan jumlah kemunculan feature pada suatu dokumen dan mempertimbangkan jumlah feature yang tidak muncul dalam dokumen. Metode TF.CHI dipilih untuk diuji karena pada penelitian yang menganalisis metode pembobotan TF.CHI dan TF.RF untuk kategorisasi teks berbahasa Indonesia menghasilkan kesimpulan bahwa metode TF.CHI lebih baik dibandingkan dengan metode TF.RF [6]. Sedangkan untuk metode TF.ABS dipilih sebagai perbandingan karena pada penelitian yang meningkatkan metode pembobotan untuk kategorisasi teks menghasilkan kesimpulan bahwa metode TF.ABS lebih baik dibandingkan dengan metode TF.IDF, TF.IG, dan sebagainya [7]. Oleh karena itu, pada penelitian ini melakukan kategorisasi berita menggunakan metode pembobotan TF.ABS dan TF.CHI untuk mengetahui metode pembobotan manakah yang menghasilkan performansi lebih baik dan mengetahui pengaruh dari proses stemming terhadap performansi dengan menggunakan metode klasifikasi Support Vector Machine (SVM) dan menggunakan $k$-Fold Cross Validation. Metode klasifikasi SVM dipilih karena metode SVM sudah diakui bahwa metode SVM lebih baik atau efektif dibandingkan dengan metode klasifikasi yang lainnya untuk klasifikasi teks [8]. Konsep dari metode SVM ini adalah mencari hyperplane terbaik yang berfungsi sebagai pemisah antar kategori atau topik dan didasari oleh prinsip structural risk minimization [9].

\section{STUDi TERKAIT}

Seiring berjalannya waktu, telah banyak penelitian yang mengambil topik kategorisasi teks dengan berbagai metode klasifikasi. Salah satunya yaitu penelitian yang menggunakan metode klasifikasi Support Vector Machine, k-Nearest Neighbor, Linear Least Square Fit, Neural Network, dan Naive Bayes sebagai pembanding performansi untuk kategorisasi. Dengan menggunakan dataset dari Reuters-21578, penelitian ini menghasilkan kesimpulan bahwa metode klasifikasi SVM lebih baik atau efektif dibandingkan dengan metode klasifikasi yang lainnya untuk kategorisasi teks [8].

Untuk meningkatkan performansi dari kategorisasi teks, banyak penelitian juga yang berfokus kepada pemberian bobot kata untuk menunjukkan tingkat kepentingannya terhadap kategori yang ada dan mendapatkan hasil performansi yang lebih optimal. Hal ini dikenal dengan istilah proses term weighting, Matsunaga dan Ebecken melakukan sebuah penelitian tentang metode pembobotan untuk kategorisasi teks dengan membandingkan metode TF.ABS, TF.IDF, TF.IG, TF.GR, TF.BNS, TF.OR, dan TF.QUI [7]. 
Penelitian ini menggunakan dataset dari Federal District Legislative Assembly di Brazil pada tahun 20032004 [10]. Hasil yang diperoleh dari penelitian ini menunjukkan bahwa metode pembobotan TF.ABS lebih baik dibandingkan dengan metode lainnya.

Pada penelitian yang menggunakan 20Newsgroup sebagai dataset untuk kategorisasi teks dengan menggunakan metode pembobotan TF.IDF dan TF.RF menghasilkan kesimpulan bahwa secara umum metode TF.RF lebih unggul dari metode TF.IDF disebagian pengujian yang dilakukan. Kelebihan TF.RF yang memperhitungkan frekuensi kemunculan suatu term pada suatu kategori dan menormalisasikannya ke keseluruhan dokumen, membuat metode ini lebih baik dibanding TF.IDF [11]. Penelitian lainnya menunjukkan bahwa metode pembobotan TF.CHI lebih baik dibandingkan dengan metode TF.RF terhadap kategorisasi teks berbahasa Indonesia dengan menggunakan metode klasifikasi Support Vector Machine [6].

\section{Metode Penelitian}

Sistem yang dibangun pada penelitian ini memiliki masukan berupa berita yang berbahasa inggris dari Reuters tahun 1987 (Reuters-21578), AG News, dan BBC News. Masing-masing sumber berita memiliki sistemnya tersendiri karena adanya perbedaan format dataset yang membuat proses load data berbeda. Sistem kemudian dapat melakukan document preprocessing yang terdiri dari word tokenization, case folding, stopwords removing, word stemming. Proses stemming dapat dilakukan atau tidak berdasarkan skenario yang diuji. Setelah proses preprocessing selesai, maka dilanjutkan ke tahap ekstraksi fitur dengan menggunakan unigram binary dan dua metode pembobotan yaitu metode TF.ABS dan TF.CHI. Proses term weighting menghasilkan tiga file yang bertipe *.csv (file untuk unigram binary, TF.ABS, dan TF.CHI). Setelah mendapatkan file tersebut, maka dilakukan proses classification dengan menggunakan metode klasifikasi Support Vector Machine (SVM) dengan tools LibSVM yang diintegrasikan pada sistem yang dibangun. Pada proses classification ini menggunakan $K$-Fold Cross Validation untuk pembagian data training dan testing dengan nilai $\mathrm{k}$ sebesar lima. Hasil performansi didapatkan setelah proses classification selesai yaitu nilai akurasi dari unigram binary dan masing-masing metode pembobotan. Berikut ini merupakan gambaran dari sistem yang dibangun.

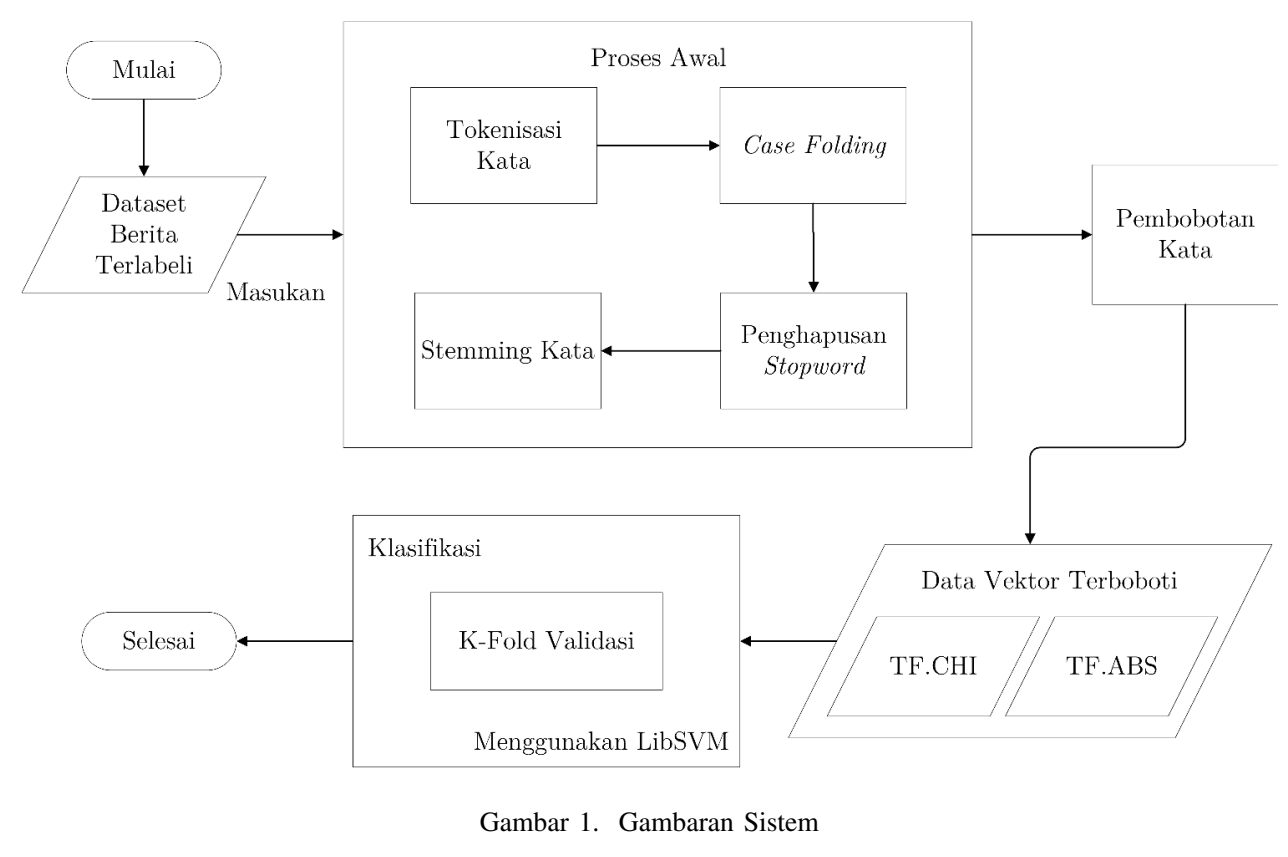


M.Arif KurniaWAn et.al.

\section{A. Dataset}

Dataset yang digunakan merupakan berita yang berbahasa inggris dari tiga sumber yang sudah terlabeli. Dataset pertama berasal dari ApteMod Reuters-21578 yang berjumlah 10788 data berkategori 90, dengan pembagian data training sebanyak 7769 dan data test sebanyak 3019 yang didapatkan dari http://search. cpan.org/ kwilliams/reuters-21578/. Kategori tersebut dirubah menjadi enam kategori yaitu corporate, commodity, economic, energy, currency, dan subject berdasarkan kategori deksripsi dari Reuters-21578. Pada penelitian ini menggunakan data test Reuters-21578 yang dikurangin dengan data berkategori currency yang berjumlah 42, sehingga dataset yang digunakan berjumlah 2977 yang memuat lima topik yaitu corporate, commodity, economic, energy, dan subject. Dataset yang kedua berasal dari BBC News yang berjumlah 2225 data dengan lima topik (business, entertertainment, politic, sport, dan tech) dari tahun 2004-2005 [12]. Jumlah masing-masing dari kategorinya dikurangin sebanyak 100, sehingga dataset BBC yang digunakan berjumlah 1725. Untuk dataset yang terakhir berasal dari AG News yang dibuat oleh Xiang Zhang berjumlah 120000 untuk train dan 7600 untuk test [13]. Data test digunakan sebagai dataset penelitian dengan mengurangi masing-masing kategori sebanyak 950, sehingga jumlah dataset AG sebanyak 3800 dengan empat topik yaitu world, sport, business, dan sci/tech. Pengurangan dari jumlah dataset aslinya dilakukan untuk kelancaran saat menjalankan sistem dengan menyesuaikan hardware sistem penulis. Pembagian jumlah masing-masing topik berdasarkan sumbernya dapat dilihat pada Tabel I.

Tabel I

Pembagian Dataset

\begin{tabular}{|c|c|c|c|c|c|c|}
\hline \multirow{2}{*}{} & \multicolumn{2}{|c|}{ Reuters 21578 } & \multicolumn{2}{c|}{ BBC News } & \multicolumn{2}{c|}{ AG News } \\
\cline { 2 - 7 } & Topik & Jumlah & Topik & Jumlah & Topik & Jumlah \\
\hline & Corporate & 1786 & Politics & 317 & World & 950 \\
\hline & Commodity & 443 & Business & 410 & Sport & 950 \\
\hline & Economic & 246 & Entertainment & 286 & Business & 950 \\
\hline & Energy & 209 & Sport & 411 & Sci/Tech & 950 \\
\hline & Subject & 293 & Tech & 301 & & \\
\hline Total & & 2977 & & 1725 & & 3800 \\
\hline
\end{tabular}

\section{B. Preprocessing}

Preprocessing dilakukan setelah proses load data selesai untuk mereduksi variansi feature yang terdiri dari word tokenization, case folding, stopwords removing, word stemming. tokenization merupakan tahapan pertama pada preprocessing yang melakukan pemotongan kalimat yang ada dalam dokumen menjadi tiap kata [14]. Tahapan selanjutnya yaitu case folding yang mengubah semua kata menjadi huruf kecil dan menghilangkan karakter selain huruf a sampai dengan z [15]. Setelah itu, stopword removing dilakukan dengan menghilangkan kata yang tidak penting seperti kata sandang dan kata hubung yang terdiri dari 571 kata berdasarkan http://search.cpan.org/ kwilliams/reuters-21578/. Word stemming merupakan tahapan akhir dari preprocessing yang mengubah kata menjadi kata dasarnya menggunakan algoritma Porter, tahapan ini dapat dilakukan atau tidak berdasarkan skenario yang diuji.

\section{Term Weighting}

Pada dasarnya, kita dapat menggunakan model N-Gram untuk memberikan nilai pada masing-masing feature dalam kategorisasi teks. Salah satu model N-Gram yang umum digunakan adalah 1-Gram yang dikenal dengan istilah unigram binary. Model tersebut memberikan nilai feature dengan nilai binary, nilai 1 menunjukkan bahwa kata tersebut terdapat dalam berita. Sedangkan nilai 0 menunjukkan bahwa kata tersebut tidak ada dalam berita itu [4]. Tabel II merupakan distribusi yang diamati untuk term $t_{j}$ dan kategori $c_{i}$. 
Tabel II

Contingency Table UNTUK category DAN term

\begin{tabular}{|c|l|l|l|}
\hline & \multicolumn{1}{|c|}{$c_{i}$} & \multicolumn{1}{c|}{$c_{\bar{i}}$} & Total \\
\hline$t_{j}$ & $n_{i j}$ & $n_{\bar{i} j}$ & $n_{j}$ \\
\hline$t_{\bar{j}}$ & $n_{i \bar{j}}$ & $n_{\bar{i} \bar{j}}$ & $n_{\bar{j}}$ \\
\hline Total & $n_{i}$ & $n_{\bar{i}}$ & $n$ \\
\hline
\end{tabular}

Keterangan variabel:

$n_{i j}$ : Merupakan jumlah dokumen dalam kategori $c_{i}$ yang mengandung term $t_{j}$

$n_{\bar{i} j}$ : Merupakan jumlah dokumen tidak dalam kategori $c_{i}$ yang mengandung term $t_{j}$

$n_{i \bar{j}}$ : Merupakan jumlah dokumen dalam kategori $c_{i}$ yang tidak mengandung term $t_{\bar{j}}$

$n_{\bar{i} \bar{j}}$ : Merupakan jumlah dokumen tidak dalam kategori $c_{\bar{i}}$ yang tidak mengandung term $t_{\bar{j}}$

$n_{j}$ : Merupakan jumlah dokumen dengan term $t_{j}$

$n_{\bar{j}}$ : Merupakan jumlah dokumen tanpa term $t_{\bar{j}}$

$n_{i}$ : Merupakan jumlah dokumen dengan kategori $c_{i}$

$n_{\bar{i}}$ : Merupakan jumlah dokumen tanpa kategori $c_{\bar{i}}$

$n$ : Merupakan total atau jumlah dari dokumen

$t_{j}$ : Merupakan term $t_{j}$

$c_{i}$ : Merupakan kategori $c_{i}$

$t_{\bar{j}}:$ Merupakan tanpa term $t_{\bar{j}}$

$c_{\bar{i}}$ : Merupakan tanpa kategori $c_{\bar{i}}$.

Pada tahapan ini, feature dari hasil preprocessing akan diberi bobot dan menyimpannya menjadi representasi vektor agar dapat digunakan sebagai masukan di klasifier. Bobot nilai ini menjadi sebuah ukuran besarnya jumlah dan tingkat kontribusi sebuah kata atau term terhadap penentuan suatu kelas atau kategori suatu dokumen [5]. Pembobotan ini menggunakan dua metode yaitu metode TF.ABS dan TF.CHI. Metode TF.ABS merupakan perkalian antar dua metode yaitu metode TF dan metode ABS. Begitu pula metode TF.CHI yaitu perkalian antar metode TF dengan CHI.

Setiap term diasumsikan memiliki proporsi kepentingan sesuai dengan jumlah kemunculannya pada suatu dokumen merupakan suatu cara dari pemberian bobot dengan metode Term Frequency (TF) [16]. ABS merupakan pengukuran kemungkinan suatu term $t_{j}$ yang ada dalam dokumen dengan kategori $c_{i}$ dibagi dengan kemungkinan term $t_{j}$ yang tidak ada dalam dokumen dengan kategori tersebut dan menerapkan transformasi logaritmik (basis log e) yang dikenal dengan logit [7]. Perhitungan Abs-logit dengan term $t_{j}$ dan category $c_{i}$ dapat dilihat pada Persamaan 1.

$$
A B S L\left(t_{j}, c_{i}\right)=\left|\ln \left(\frac{\left(n_{i j}+0.5\right)\left(n_{\bar{i} \bar{j}}+0.5\right)}{\left(n_{\bar{i} j}+0.5\right)\left(n_{i \bar{j}}+0.5\right)}\right)\right|
$$

Chi-Square merupakan suatu metode supervised yang membutuhkan informasi berasal dari kategori mana suatu dokumen tersebut. Metode ini mempertimbangkan bobot untuk term yang tidak muncul dalam dokumen dan term yang muncul didalam dokumen [17]. Pembobotan Chi-Square dengan term $t_{j}$ dan kategori $c_{i}$ dapat dilihat pada Persamaan 2.

$$
\chi^{2}\left(t_{j}, c_{i}\right)=\frac{n\left(n_{i j} n_{\bar{i} \bar{j}}-n_{\bar{i} j} n_{i \bar{j}}\right)^{2}}{n_{i} n_{j} n_{\bar{i}} n_{\bar{j}}}
$$

\section{Classification}

Classification merupakan tahapan terakhir yang menggunakan metode klasifikasi Support Vector Machine (SVM) dengan tools LibSVM. Support Vector Machine merupakan suatu metode machine learning yang mencari hyperplane terbaik yang berfungsi sebagai pemisah antar topik. Hyperplane terbaik dapat ditemukan dengan mengukur margin hyperplane tersebut dengan pattern terdekat (support vector) dari masing-masing topik [9]. Data masukan akan dibagi menjadi data training dan testing menggunakan 
M.Arif KurniaWAn et.al.

Kategorisasi Berita menggunakan Metode...

K-Fold Cross Validation dengan nilai k sebesar lima, yang berarti membagi dataset menjadi lima buah partisi secara acak (data-1, data-2,..., data-5) [18]. Proses Classification dari sistem menghasilkan output berupa hasil performansi dari unigram binary dan masing-masing metode pembobotan.

\section{HASIL DAN ANALISIS}

Pengujian dalam penelitian ini dilakukan dengan dua skenario, skenario pertama ditujukan untuk menemukan metode pembobotan manakah yang lebih baik diantara metode TF.ABS dan TF.CHI. Sedangkan skenario kedua ditujukan untuk mengetahui pengaruh proses stemming terhadap performansi kategorisasi berita pada penelitian ini.

\section{A. Hasil Pengujian dan Analisis Skenario 1}

Skenario 1 bertujuan untuk mengetahui metode pembobotan yang lebih baik diantara TF.ABS dan TF.CHI, skenario ini dilakukan tanpa menerapkan proses stemming dengan menggunakan metode pembobotan TF.ABS dan TF.CHI. Penelitian ini menggunakan metode unigram binary sebagai pembanding dasar sebelum dibobotin dari kedua metode pembobotan tersebut. Hasil pengujian skenario 1 dapat dilihat pada Tabel III.

Tabel III

HASIL AKURASI TANPa Stemming

\begin{tabular}{|c|l|c|c|c|c|c|c|}
\hline \multirow{2}{*}{ No } & \multirow{2}{*}{ Dataset } & \multirow{2}{*}{ N Data } & \multirow{2}{*}{ N Topik } & \multirow{2}{*}{ N kata } & \multicolumn{3}{|c|}{ Akurasi tanpa Stemming (\%) } \\
\cline { 6 - 8 } & & & & & Unigram Binary & TF.ABS & TF.CHI \\
\hline 1 & Reuters 21578 & 2977 & 5 & 16994 & 93.08 & 95.6 & 95.84 \\
\hline 2 & BBC News & 1725 & 5 & 27712 & 96.75 & 99.07 & 99.25 \\
\hline 3 & AG News & 3800 & 4 & 14840 & 81.5 & 92.55 & 92.53 \\
\hline & & & & Rata-rata & 90.44 & 95.74 & 95.87 \\
\hline
\end{tabular}

Berdasarkan rata-rata akurasi pada Tabel III, metode pembobotan TF.ABS dan TF.CHI dapat meningkatkan performa sistem bila dibandingkan dengan unigram binary yaitu sebesar 5\%. Hal ini dikarenakan unigram binary hanya menggunakan nilai biner yang menandakan feature tersebut ada pada dokumen, sedangkan metode pembobotan memberikan nilai feature yang ada pada dokumen dengan memperhitungkan tingkat kontribusinya. Akurasi metode TF.CHI lebih baik dibandingkan dengan metode TF.ABS untuk dataset yang bersumber dari Reuters-21578 dan BBC News. Sedangkan pada dataset AG News, metode TF.ABS lebih baik dibandingkan dengan TF.CHI. Perbedaan peningkatan diantara kedua metode tersebut kurang dari $1 \%$, hal ini dapat dilihat pula pada rata-rata akurasi antar metode pembobotan yaitu sebesar $95.74 \%$ untuk metode TF.ABS dan 95.87\% untuk metode TF.CHI. Kedua metode pembobotan tidak memberikan beda yang signifikan karena sama-sama mempertimbangkan term $t_{j}$ yang muncul maupun tidak muncul dalam dokumen.

\section{B. Hasil Pengujian dan Analisis Skenario 2}

Pada pengujian skenario 1, sistem membutuhkan waktu proses yang cukup lama. Oleh sebab itu dilakukannya skenario 2 yang bertujuan untuk mengetahui pengaruh proses stemming dengan menggunakan metode pembobotan TF.ABS dan TF.CHI. Penelitian ini menerapkan proses stemming sebagai pembanding dengan skenario 1 yang tidak menggunakan proses stemming. Perbedaan waktu proses pembobotan dan klasifikasi antara skenario 1 dengan skenario 2 dapat dilihat pada Gambar 2, sedangkan perbandingan hasil akurasi diantara kedua skenario dapat dilihat pada Tabel IV. 


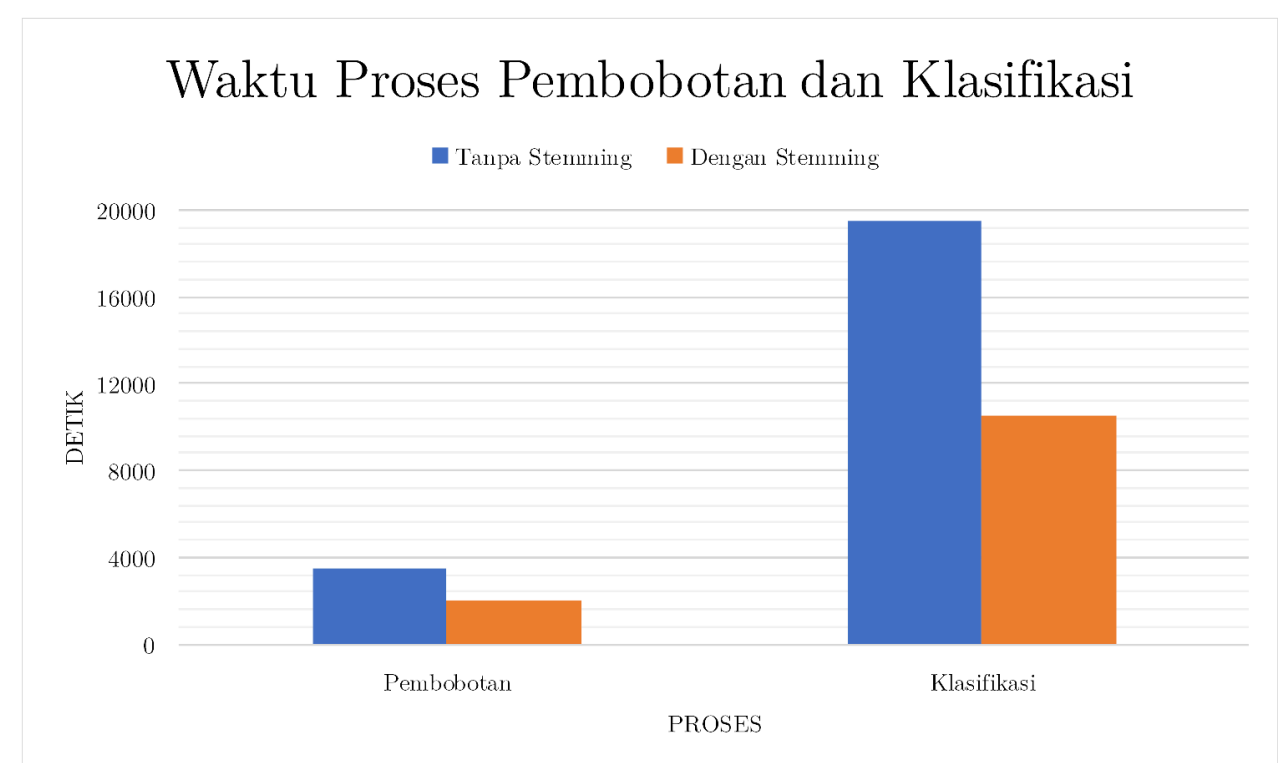

Gambar 2. Waktu Proses Pembobotan dan Klasifikasi

Tabel IV

HaSil AKURASI DENGAN Stemming

\begin{tabular}{|c|l|c|c|c|c|c|c|}
\hline \multirow{2}{*}{ No } & \multirow{2}{*}{ Dataset } & \multirow{2}{*}{ N Data } & \multirow{2}{*}{ N Topik } & \multirow{2}{*}{ N kata } & \multicolumn{3}{|c|}{ Akurasi dengan Stemming (\%) } \\
\cline { 5 - 8 } & & & & & Unigram Binary & TF.ABS & TF.CHI \\
\hline 1 & Reuters 21578 & 2977 & 5 & 12505 & 93.22 & 96.17 & 97.08 \\
\hline 2 & BBC News & 1725 & 5 & 18991 & 97.51 & 99.13 & 99.48 \\
\hline 3 & AG News & 3800 & 4 & 11072 & 81.74 & 92.13 & 91.71 \\
\hline & & & & Rata-rata & 90.82 & 95.81 & 96.09 \\
\hline
\end{tabular}

Tabel IV menunjukkan bahwa rata-rata hasil akurasi dengan proses stemming untuk unigram binary sebesar $90.82 \%$, sedangkan untuk metode pembobotan TF.ABS sebesar $95.81 \%$ dan TF.CHI sebesar 96.09\%. Bila dibandingkan dengan hasil akurasi tanpa proses stemming pada Tabel III, proses stemming dapat memberikan peningkatan akurasi kurang dari $1 \%$. Peningkatan yang tidak terlalu signifikan ini dikarenakan perbandingan jumlah data dengan jumlah kata antar dataset, jumlah data yang kecil dan jumlah kata yang banyak akan menghasilkan akurasi yang lebih baik dibandingkan dengan jumlah data yang banyak dan jumlah kata yang kecil. Pada Gambar 2, tanpa stemming merupakan rata-rata waktu proses dari 3 sumber tanpa menerapkan proses stemming. Sedangkan dengan stemming merupakan ratarata waktu yang menerapkan proses stemming. Gambar 2 menunjukkan bahwa proses stemming dapat mengefisiensikan waktu hingga $45 \%$ pada proses pembobotan dan klasifikasi. Hal ini dikarenakan proses stemming dapat mengurangi jumlah kata dari dataset hingga 30\% yang dapat dilihat perbandingannya pada Tabel III dengan Tabel IV.

\section{KESIMPULAN}

Berdasarkan dari hasil pengujian dan analisis di atas, maka kesimpulan yang didapatkan pada penelitian ini sebagai berikut:

1) Kategorisasi berita tanpa menerapkan proses stemming dengan menggunakan unigram binary menghasilkan nilai rata-rata akurasi sebesar $90.44 \%$. Sedangkan bila menggunakan metode pembobotan TF.ABS menghasilkan nilai akurasi sebesar $95.74 \%$ dan untuk metode pembobotan TF.CHI sebesar 95.87\%. Berdasarkan dari nilai akurasi tersebut dapat disimpulkan bahwa metode pembobotan lebih baik dibandingkan dengan unigram binary dengan memberikan peningkatan sebesar 5\%, hal ini 
M.Arif KurniaWAN Et.AL.

Kategorisasi Berita menggunakan Metode...

dikarenakan unigram binary hanya menggunakan nilai biner yang menandakan feature tersebut ada pada dokumen, sedangkan metode pembobotan memberikan nilai feature yang ada pada dokumen dengan memperhitungkan tingkat kontribusinya. Metode pembobotan TF.CHI dan TF.ABS tidak memberikan beda yang signifikan dalam performansi, hal ini menunjukkan bahwa kedua metode tersebut sama-sama baik dalam kategorisasi berita karena mempertimbangkan feature yang muncul maupun tidak dalam dokumen.

2) Proses stemming pada tahap preprocessing tidak memberikan banyak pengaruh terhadap akurasi dari kategorisai berita dengan menggunakan metode pembobotan TF.ABS dan TF.CHI. Proses stemming hanya memberikan peningkatan akurasi kurang dari 1\%, namun proses ini mereduksi jumlah kata yang dapat mengefisiensikan waktu proses pembobotan dan klasifikasi hingga $45 \%$. Peningkatan yang tidak terlalu signifikan dalam akurasi ini dikarenakan perbandingan jumlah data dengan jumlah kata antar dataset, jumlah data yang kecil dan jumlah kata yang banyak akan menghasilkan akurasi yang lebih baik dibandingkan dengan jumlah data yang banyak dan jumlah kata yang kecil.

Penelitian ini menunjukkan bahwa feature yang didapatkan dari masing-masing sumber dataset berjumlah cukup banyak. Oleh sebab itu, penelitian selanjutnya dapat menggunakan feature selection untuk memilih fitur yang berpengaruh dan mengurangi feature yang kurang relevan. Selain itu, penelitian kedepannya dapat menggunakan dataset yang berbeda seperti 20 Newsgroup dan Classifier yang lainnya sebagai pembanding performansi dari metode TF.ABS dan TF.CHI.

\section{PUSTAKA}

[1] A. Basu, C. Watters, and M. Shepherd. Support Vector Machines for Text Categorization. IEEE, 2003.

[2] C. Goutam. Analysis of Unstructured Data: Applications of Text Analytics and Sentiment Mining. 2014.

[3] F. Ismail. Examining Learning Algorithms for Text Classification in Digital Libraries. Department of Alfa-Informatica, University of Groningen. Netherland, 2004.

[4] T. Christoph and X. Fei. A phrase-based unigram model for statistical machine translation. Association for Computational Linguistics Stroudsburg, PA, USA, 2003.

[5] M. Liliam Ayako and E. Nelson Francisco Favilla. Two Novel Weighting for Text Categorization. WITPress, 2008.

[6] E. Putri N Kianiseta. Analisis Perbandingan Metode Pembobotan TF.CHI2 dan TF.RF Terhadap Kategorisasi Teks Berbahasa Indonesia. Universitas Telkom, 2014.

[7] M. Liliam Ayako and E. Nelson Francisco Favilla. Term Weighting Approaches for Text Categorization Improving. IEEE, 2008.

[8] Y. Yiming and L. Xin. An Re-examination of Text Categorization. ACM New York, NY, USA, 1999.

[9] W. Ziqiang, S. Xia, and Z. Dexian. An Optimal Text Categorization Algorithm Based on SVM. IEEE, 2007.

[10] M. Liliam Ayako. An Automated Text Categorization Methodology to Distribute the Bills to the Commettees at the Federal Distric Legislative Assembly. Dept of Civil Engineering, COPPE/Federal University of Rio de Janeiro, 2007.

[11] A. Thopo Martha. Analisis Perbandingan Metode Pembobotan Kata TF.IDF dan TF.RF Terhadap Performansi Kategorisasi Teks. Universitas Telkom, 2012.

[12] G. Derek and C. Padraig. Practical Solutions to the Problem of Diagonal Dominance in Kernel Document Clustering. ICML, 2006.

[13] Z. Xiang, Z. Junbo, and L. Yann. Character-level Convolutional Networks for Text Classification. NIPS, 2015.

[14] M. Christopher D., R. Prabhakar, and S. Hinrich. Introduction to Information Retrieval. Cambridge University Press, 2008.

[15] N. Nadia. Intelligent Text Categorization and Clustering. Berlin: Springer, 2009.

[16] T. Tokunaga and I. Makoto. Text Categorization Based On Weighted Inverse Document Frequency. Tokyo, Japan: Tokyo Institute of Technology, 1994.

[17] S. Catur and Affandy. Kombinasi Teknik Chi Square dan Singular Value Decomposition Untuk Reduksi Fitur Pada Pengelompokan Dokumen. Melaka, Malaysia : Universitas Teknikal Malaysia, 2011.

[18] Y. Sanjay and S. Sanyam. Analysis of k-Fold Cross-Validation over Hold-Out Validation on Colossal Datasets for Quality Classification. IEEE, 2016. 